\title{
Disease Detection and Diagnosis on Plant using Image Processing - A Review
}

\author{
Khushal Khairnar \\ Department of Computer Engineering, \\ Marathwada Mitra Mandal's College of Engineering \\ Pune
}

\author{
Rahul Dagade \\ Department of Computer Engineering, \\ Marathwada Mitra Mandal's College of Engineering, \\ Pune
}

\begin{abstract}
Diseases decrease the productivity of plant. Which restrict the growth of plant and quality and quantity of plant also reduces. Image processing is best way for detecting and diagnosis the diseases. In which initially the infected region is found then different features are extracted such as color, texture and shape. Finally classification technique is used for detecting the diseases. There are different feature extraction techniques for extracting the color, texture and edge features such as color space, color histogram, grey level co-occurrence matrix (CCM), Gabor filter, Canny and Sobel edge detector. There are also different classification techniques such as Support Vector Machine (SVM), Artificial Neural Network (ANN), Backpropagation (BP) Network, Probabilistic Neural Network (PNN), Radial Basis Function (RBF) Neural Network.
\end{abstract}

\section{General Terms}

Image Processing, Disease Detection

\section{Keywords}

Feature Extraction, Classification, Support Vector Machine, Neural Network.

\section{INTRODUCTION}

India is agriculture country where in more than $65 \%$ population depends on agriculture. The crop losses due to diseases are approximately 10 to $30 \%$. Farmers judge the diseases by their experience but this is not accurate and proper way. Sometimes farmers call the experts for detecting the diseases but this also time consuming way. The diseases mostly on leaves and on stem of plant. The diseases are viral, bacterial, fungal, diseases due to insects, rust, nematodes etc. on plant. It is important task for farmers to find out these diseases as early as possible. Following example shows that how diseases on cotton plant reduces the productivity. There is 20 to $25 \%$ of cotton loss due to diseases on plant[8].

Accurate, automatic and rapid method for detecting the diseases is required.

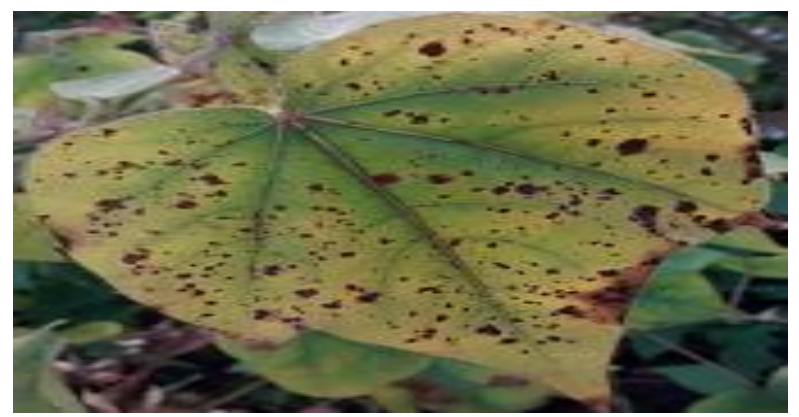

Figure 1. Infected leaf of cotton plant
This review paper provides an overview of different features extraction and classification techniques for plant disease detection and classification.

\section{LITERATURE REVIEW}

Various papers describing to detecting the diseases and methods suggesting the implementation ways as illustrated and discussed here.

Detection of Diseases on Cotton Leaves and Its Possible Diagnosis by Mr. V. A. Gulhane \& Dr. A. A. Gurjar, [1]. Where the color and spot features could be extracted using self organizing feature map together with a back-propagation neural network.

Detection of unhealthy region of plant leaves and classification of plant leaf diseases using texture features by $\mathrm{S}$. Arivazhagan, et al[2] developed processing scheme in which a color transformation structure for the input RGB image is created, and then the green pixels are masked. Shape and texture features are extracted.

The classification is done by using the Minimum Distance Criterion and Support vector machines (SVMs).

Dheeb Al Bashish,et al.[3], have proposed A Framework for Detection and Classification of Plant leaf and Stem Diseases in which the images at hand are segmented using the $\mathrm{K}$ Means technique, RGB input images are converted into HIS color space. Then calculating color and texture based features. Neural network classifier that is based on statistical classification is used for classification.

Elham Omrani, et al[4] have proposed Potential of radial basis function-based support vector regression for apple disease detection, detection of leaf diseases has been used method is threefold:

First the leaf images were stored in RGB - a devicedependent color space. To segment the images, they had to be transferred to the device-independent color space CIELAB. Second in order to extract the infected area, region-based segmentation was employed. K-means cluster is an important technique implemented in the segmentation phase. Third to extract the color, shape and texture-based features. They are normally used for region description. To obtain the texture features, wavelet and gray level co-occurrence matrix techniques were employed.

A support vector regression (SVR) technique to classify apple leaf diseases.

Haiguang Wang, et al[5] have proposed Image Recognition of Plant Diseases Based on Principal Component Analysis and Neural Networks in which 21 color features, 4 shape features and 25 texture features were extracted from the images of wheat and grape diseases. This features are extracted by 
principal component analysis (PCA). neural networks including backpropagation (BP) networks, radial basis function (RBF) neural networks, generalized regression networks (GRNNs) and probabilistic neural networks (PNNs) were used as the classifiers to identify wheat diseases and grape diseases, respectively.

Santanu Phadikar, et al[6], have proposed Rice Disease Identification using Pattern Recognition Techniques describes a software prototype system for rice disease detection based on the infected images of various rice plants. Using digital camera images of infected rice plants are captured and using image growing, image segmentation techniques to detect infected parts of the plants. Then the classification of infected part of leaf is done by neural network.

P. Revathi, et al[7] have proposed Cotton Leaf Spot Diseases Detection Utilizing Feature Selection with Skew Divergence Method in this work enhanced PSO feature selection method adopts skew divergence method and to extract Edge, CYMK color feature, GA feature, Color, Texture variances features. The extracted feature was input to the SVM, Back propagation neural network (BPN), Fuzzy with Edge selection and classification is done by them.

\section{METHODOLOGY}

The step-by-step procedure as shown below:

\section{Image acquisition}

Firstly, the RGB color images are captured using a digital camera with required resolution for good quality. The construction of an image database is clearly dependent on the application. The image database itself is responsible for the better efficiency of the classifier which decides the robustness of the algorithm.

\section{Image Preprocessing and Segmentation}

In preprocessing step to improve image data that removes background, noise and also suppress undesired distortions. It enhances image features for processing and analysis.

The input RGB color image is converted into other color spaces such as HIS and CIELAB. Because RGB is color dependent space model but HSI and CIELAB are color independent space model and this are also derived from human perception.

In segmentation step to find out the infected region. Segmentation mostly can be done by k-mean clustering, edge detection algorithm.

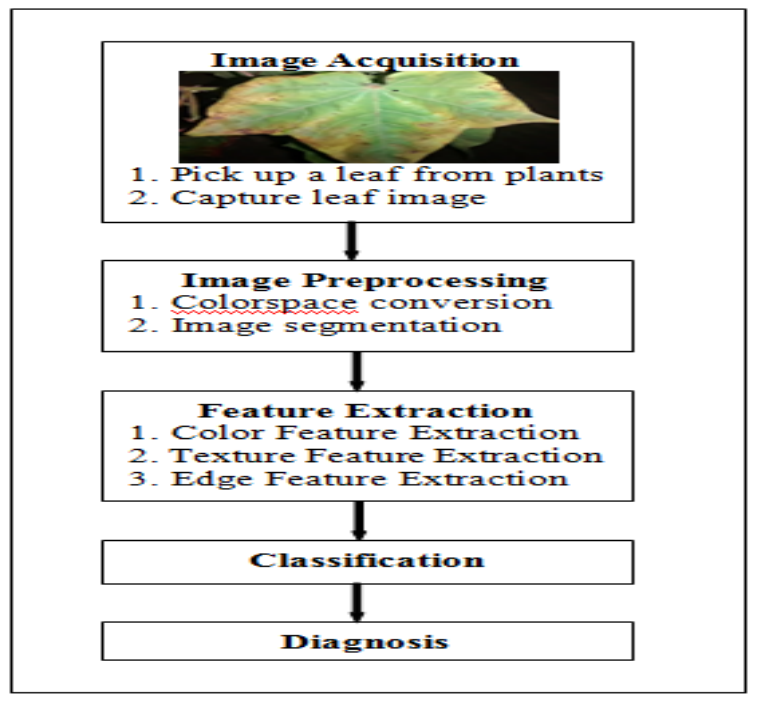

Figure 2. The Basic Steps for Disease Detection Algorithm

\section{Feature Extraction}

After segmentation the infected region various features are extracted to describe the infected region. Color, texture and shape based features are normally used for region description.

Color features are important to sense image environment, recognize objects and convey information[9].

Texture is one of the most important feature which can be used to classify and recognize objects. It is a powerful regional descriptor that helps in the image retrieval process. Contrast, Homogeneity, Dissimilarity, Energy and Entropy features are intended to describe texture. Shape is one of the primitive features for image content description.

\section{Classification}

It is final stage in disease detection. It is identifying a rule according to selected features and assigning each disease to any one the predetermined classes [4]. The Artificial Neural Network and Support Vector Machine are mostly used as classifier

\section{SUMMARY ON LITERATURE SURVEY}

Here some features, there extraction techniques and classifiers are discussed:

Table 1. Summary of Literature Survey

\begin{tabular}{|c|c|c|c|c|}
\hline Paper & $\begin{array}{l}\text { Features } \\
\text { Extraction }\end{array}$ & $\begin{array}{l}\text { Feature } \\
\text { Technique }\end{array}$ & Classifier & Plant \\
\hline $\begin{array}{l}\text { V. A. Gulhane, } \\
\text { et al[1] }\end{array}$ & $\begin{array}{l}\text { 1. color } \\
\text { 2. shape of holes }\end{array}$ & $\begin{array}{l}\text { Unsupervised } \\
\text { organizing feature map. }\end{array}$ & ANN & Cotton \\
\hline $\begin{array}{l}\text { S. Arivazhagan, } \\
\text { et al[2] }\end{array}$ & $\begin{array}{l}\text { 1. Color } \\
\text { 2. Texture }\end{array}$ & $\begin{array}{l}\text { Color-Co-Occurrence } \\
\text { methodology }(\mathrm{CCM})\end{array}$ & SVM. & Native plant species \\
\hline $\begin{array}{l}\text { Dheeb Al } \\
\text { Bashish, et al[3] }\end{array}$ & $\begin{array}{l}\text { 1. Color } \\
\text { 2. Texture }\end{array}$ & $\mathrm{CCM}$ & ANN & $\begin{array}{l}\text { Five diseases which effect on the } \\
\text { plants; they are: } \\
\text { Early scorch, Cottony mold, Ashen } \\
\text { mold, late scorch, tiny whiteness. }\end{array}$ \\
\hline $\begin{array}{l}\text { Elham Omrani, } \\
\text { et al[4] }\end{array}$ & $\begin{array}{l}\text { 1. Color } \\
\text { 2. shape } \\
\text { 3. Texture }\end{array}$ & $\begin{array}{l}\text { Wavelet transform, SGDM } \\
\text { and CCM. }\end{array}$ & $\begin{array}{l}\text { support vector } \\
\text { regression }(\mathrm{SVR})\end{array}$ & Apple \\
\hline $\begin{array}{l}\text { Haiguang Wang, } \\
\text { et al[5] }\end{array}$ & $\begin{array}{l}\text { 1. Color } \\
\text { 2. Texture } \\
\text { 3. Shape }\end{array}$ & $\begin{array}{l}\text { Principal component } \\
\text { analysis (PCA) }\end{array}$ & $\begin{array}{l}\text { BPNN, RBFNN, } \\
\text { GRNN and PNN }\end{array}$ & Wheat and grape diseases. \\
\hline
\end{tabular}




\begin{tabular}{|c|c|c|c|c|}
\hline $\begin{array}{l}\text { Santanu } \\
\text { Phadikar, et } \\
\text { al[6] }\end{array}$ & $\begin{array}{l}\text { 1. Boundary } \\
\text { 2. Edge } \\
\text { 3. Spot }\end{array}$ & $\begin{array}{l}\text { Boundary detection } \\
\text { algorithm }\end{array}$ & ANN & Rice \\
\hline $\begin{array}{l}\text { P. Revathi, et } \\
\text { al[7] }\end{array}$ & $\begin{array}{l}\text { 1. Edge } \\
\text { 2. CMYK color } \\
\text { 3. Texture }\end{array}$ & $\begin{array}{l}\text { Enhanced PSO and GA } \\
\text { algorithm. }\end{array}$ & SVM, BPN, Fuzzy & Cotton \\
\hline
\end{tabular}

Comments: Summary shows that for detecting the diseases on plant the features such as color, texture and edge are need to extract. ANN and SVM are classifier to recognize the diseases.

\section{CONCLUSION}

Image processing-based approach is proposed and useful for plant diseases detection. This paper describes different techniques of image processing for several plant species that have been used for detecting plant diseases.

In future work, we will develop to incorporate user-feedback into the system. In addition to explore methods for combining texture, edge and color features.

\section{REFERENCES}

[1] V. A. Gulhane, Dr. A. A. Gurjar, "Detection of Diseases on Cotton Leaves and Its Possible Diagnosis". 2011 International Journal of Image Processing (IJIP), Vol.5, Issue (5), pg.no.590-598.

[2] S. Arivazhagan, R. Newlin Shebiah, S. Ananthi, S. Vishnu Varthini, "Detection of unhealthy region of plant leaves and classification of plant leaf diseases using texture features", Agric Eng Int: CIGR Journal, Vol.15, pg.no.211-217, March 2013.

[3] Dheeb Al Bashish, Malik Braik, and Sulieman BaniAhmad, "A Framework for Detection and Classification of Plant leaf and Stem Diseases", 2012 International conference on signal and Image Processing, pg.no.113118 , Chennai, India.
[4] Elham Omrani, Benyamin Khoshnevisan, Shahaboddin Shamshirband, Hadi Saboohi, Nor Badrul Anuar, Mohd Hairul Nizam Md Nasir, "Potential of radial basis function-based support vector regression for apple disease detection", Measurement, vol.55, pg.no.512-519, Sept-2014, (Elsevier).

[5] Haiguang Wang, Guanlin Li, Zhanhong $\mathrm{Ma}$ and Xiaolong Li, "Image Recognition of Plant Diseases Based on Principal Component Analysis and Neural Networks", 8th International Conference on Natural Computation (ICNC 2012), pg.no.246-251, (IEEE).

[6] Santanu Phadikar and Jaya Sil, "Rice Disease Identification using Pattern Recognition Techniques", Proceedings of 11th International Conference on Computer and Information Technology (ICCIT 2008), 25-27 December, 2008, Khulna, Bangladesh, pg.no420423, (IEEE).

[7] P. Revathi, M. Hemalatha, "Cotton Leaf Spot Diseases Detection Utilizing Feature Selection with Skew Divergence Method", International Journal of Scientific Engineering and Technology (ISSN : 2277-1581), Vol.(3), Issue No.1, pg.no. 22-30, 1 Jan 2014.

[8] http://cotcorp.gov.in/current-cotton.aspx ?pageid=4 .

[9] Ms. Kiran R. Gavhale and Prof. Ujwalla Gawande, “ An Overview of the Research on Plant Leaves Disease detection using Image Processing Techniques", IOSR Journal of Computer Engineering (IOSR-JCE), ISSN: 2278-8727, Vol( 16), Issue 1, PP 10-16, Ver. V (Jan. 2014). 